\title{
Seasonal Distribution of Suspended Particulate Matter off China's Subei Coast
}

\author{
Zhaojun Song ${ }^{1,2 *}$, Jianping Li ${ }^{1}$, Fanxue Meng ${ }^{1}$, Wenjia Tang ${ }^{1}$, Xingyu Yuan ${ }^{1}$ \\ ${ }^{1}$ Shandong Provincial Key Laboratory of Depositional Mineralization and Sedimentary Minerals, College of Earth \\ Science and Engineering, Shandong University of Science and Technology, Qingdao, Shandong 266590, P.R. China \\ ${ }^{2}$ Laboratory for Marine Mineral Resources, Qingdao National Laboratory for Marine Science and Technology, \\ Qingdao, Shandong 266071, P.R. China
}

Received: 27 March 2017

Accepted: 11 July 2017

\begin{abstract}
In this study, the spatial distribution and seasonal changes of suspended particulate matter (SPM) concentrations near radial sand ridge areas off China's Subei Coast are addressed, based upon field measurements conducted during spring and autumn. The results show that the SPM concentrations have higher values in spring than in autumn, and that higher concentrations of SPM occur in the near-bottom layer in both seasons; also, the nearshore areas have higher concentrations of SPM than offshore. In addition, a robust linear relationship was established between the SPM concentrations $\left(\mathrm{mgL}^{-1}\right)$ and in situ remote sensing reflectance $(\mathrm{Rrs})\left(\mathrm{R}^{2}=0.944, \mathrm{n}=39\right)$, and then the concentrations of SPM are retrieved from the satellite images, which have a good corresponding relationship with in situ SPM concentrations. There are significant differences between SPM concentrations in spring and those in autumn. The SPM in the study area is mainly derived from the resuspension of the seabed sediments in the radial sand ridges (abandoned Huanghe-Changjiang River multiple delta).
\end{abstract}

Keywords: suspended particulate matter (SPM), spatial distribution, seasonal changes, remote sensing retrieval of SPM concentration, radial sand ridges off Subei Coast

\section{Introduction}

The tidal sand ridges are an important type of geomorphic unit on many continental shelves and coastal regions, and they are widely distributed in estuaries, coastal bays, and at the ends of straits [1-2]. There are some large radial sand ridges in the west of the Yellow Sea located off the Subei Coast of China between the modern Changjiang River (Yangtze River) delta in the south and the abandoned Huanghe River (old Yellow River) delta in the north (Fig. 1). It extends about $200 \mathrm{~km}$

*e-mail: songzhaojun76@163.com in length and $90 \mathrm{~km}$ in width and includes 10 large-scale linear sand ridges (including submarine sand ridges) - the largest sand ridges in China with an area of $20,000 \mathrm{~km}^{2}$ in total. This is a special geomorphology system in landform feature and in hydrodynamic conditions. The sand ridges extend to the north, northeast, east, and south; it looks fan-shaped and its top point is at the town of Qianggang. The radial sand ridges consist of more than 70 individual tidal sand ridges.

The hydrodynamic setting of the study area is dominated by the convergent-divergent tidal currents. Tidal currents are radial with flood tidal currents converging to the center of the research area and ebb currents diverging to the sea, and the tidal currents are forward and backward [3]. The tidal range is $6-7 \mathrm{~m}$ on 
average at the research apical area, with a maximum of $9.28 \mathrm{~m} / \mathrm{s}$ in the central part and the tidal range decreasing gradually toward the south and north [4]. The sea area of the radial sand ridges is well known for its special submarine topography, high SPM concentration, and complicated hydrodynamic conditions. The distribution and dispersal of SPM in the coastal areas have played important roles in the evolution of the coastal landforms [5-6] and response to anticipated future climate change [7]. Furthermore, as an important carrier of nutrients and pollutants in seawater, the distribution and migration of SPM have an important influence on marine ecological environment [8-9].

Numerous studies concerning SPM in the South Yellow Sea have been performed since the 1950s. In 1988, 1992, and 1993 three investigations were respectively conducted by the Oceanography Institute, China Academy of Science (IOCAS) [10-11]. Then a series of surveys were developed, such as the China-Korea joint investigation in 1996 [12] and the comprehensive survey and evaluation of the Yellow Sea offshore from 2006 to 2016 [13-14]. In recent years, the evolution characteristics and transportation of SPM have become a hot topic in research on the radial sand ridges. Liu et al. [15] discussed the reverse sediment transport trend between the abandoned Huanghe River (Old Yellow River) Delta and radial sand ridges. Chen et al. [16] analyzed the evolution characteristics of main waterways and their control mechanisms in the radial sand ridges. Xu et al. [17] revealed the mechanisms underlying the regional morphological differences between the northern and southern radial sand ridges along the Jiangsu Coast. As stated above, there have been many studies regarding SPM in the South Yellow Sea, but those concerning SPM near the radial sand ridge areas off the Subei Coast have been relatively scarce, especially research data in spring and autumn. Therefore, in this study the seasonal changes of SPM, as well as the retrieval of SPM concentration from satellite images, were analyzed by means of SPM samples and remote sensing reflectance data investigated near radial sand ridge areas off the Subei Coast during spring and autumn.

\section{Materials and Methods}

\section{Measuring and Processing Samples and Data}

Two cruises were carried out by the National Satellite Ocean Application Service (NSOAS) and IOCAS in spring and autumn of the same year. The locations of these field-sampling sites are shown in Fig. 1. For each survey station, each of the above-water spectrum measurements were performed with a co-coinciding water sample. Most of the measurements were taken by strictly following the Specifications for Oceanographic Survey-Marine Geology and Geophysics Investigation (GB/T 13909-92) and NASA SIMBIOS ocean optic protocols [18-19].

106 water samples were obtained in spring and 103 in autumn using a Niskin water sampling instrument. According to water depth, the water samples were obtained in from one to five layers at each sampling station, and the distance between the near-bottom layers and seabed was 5-10 m. For SPM concentrations, the water samples were filtered with a $0.45 \mu \mathrm{m}$ pore-size import filter and vacuum filtration system in the sampling area. After filtering, the water samples were kept under refrigeration conditions. Stored samples were dried (at a constant temperature of $40^{\circ} \mathrm{C}$ ), then weighed on a high-precision balance in the laboratory, and SPM concentrations were measured by determining the ratio of dry sediment weight and water volume [20]. For the inorganic component (suspended sediment), the sampled filter-pad was placed inside the crucible and burnt with ethanol, and then the crucible was covered and placed in a $500^{\circ} \mathrm{C}$ muffle oven to be combusted for $1 \mathrm{~h}$. When the sample was cooled down, it was re-scaled again to obtain the inorganic component. The grain sizes of 107 samples, which were selected from dry samples of SPM, were analyzed using the Mastersizer 2000. The analysis technique gives the grain size spectrum at a range of from $0.02 \mu \mathrm{m}$ to $2000 \mu \mathrm{m}$ with $\pm 1 \%$ accuracy. SPM grain size was determined following the procedures outlined in [21]. Rrs data derived from NSOAS and their methods of measurement and process are explained in detail by [22].

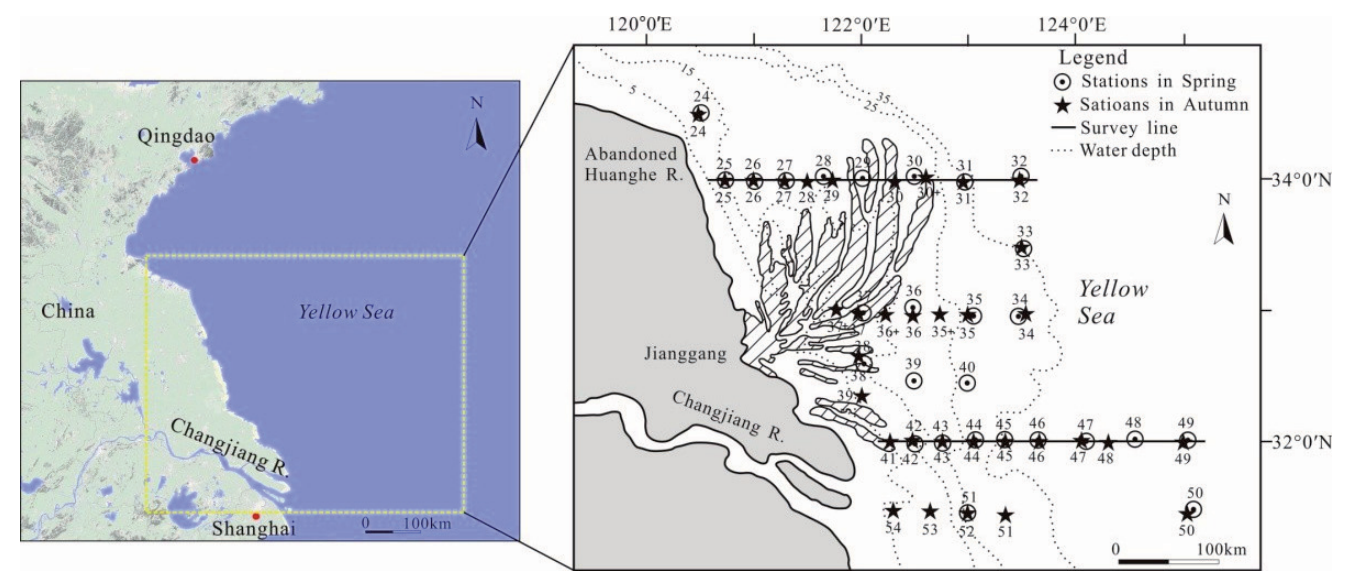

Fig. 1. Study area and sampling station locations. 


\section{Processing Satellite Imagery}

The NOAA-14 advanced very high resolution radiometer (AVHRR) data with nominal spatial resolution of $1 \mathrm{~km}$, which were downloaded from NASA (nssdc.gsfc.nasa.gov), were employed in this study. All images were preprocessed through a series of operations, including calibration, georeference, resizing data, atmospheric correction, cloud detection, etc. In addition, the atmospheric correction methodology and equations developed [23] for AVHRR-visible data and the developed cloud detection method [24] were adopted. The satellite images processed by atmospheric correction and geoference reflect water-leaving reflectance, and waterleaving reflectance can be transformed to remote sensing reflectance following the procedure described by Doxaran [25]. Therefore, the surface SPM concentrations can be retrieved from satellite images based on the relationship between the Rrs and in situ SPM concentrations.

\section{Results and Discussion}

\section{Analyses of Filed Measurement data of SPM}

In spring, the surface SPM concentration values in the radial sand ridge areas ranged from less than $10 \mathrm{mgL}^{-1}$ to more than $100 \mathrm{mgL}^{-1}$ (Fig. 2a). The highest surface SPM concentration value was $184.1 \mathrm{mgL}^{-1}$ at sampling station No. 26. The near-bottom SPM concentration with the maximum of $523.1 \mathrm{mgL}^{-1}$ was much more than 2-4 times that of the surface concentration of SPM (Fig. 2b). Acrossshore, the SPM concentration decreased remarkably.

The vertical distribution of SPM concentration is relatively complicated. On survey line $32^{\circ} \mathrm{N}$, the concentration of SPM is uniform from the surface to nearbottom layers, with the exception of sampling station No. 49 (Fig. 3a). On survey line $34^{\circ} \mathrm{N}$, the concentration of SPM at most of the sampling stations increases remarkably with water depth and decreases across-shore (Fig. 3b).

In autumn, the distribution of SPM concentration is similar to that in spring, whereas the SPM concentration values are generally lower than in spring (Figs 4(a-b). The
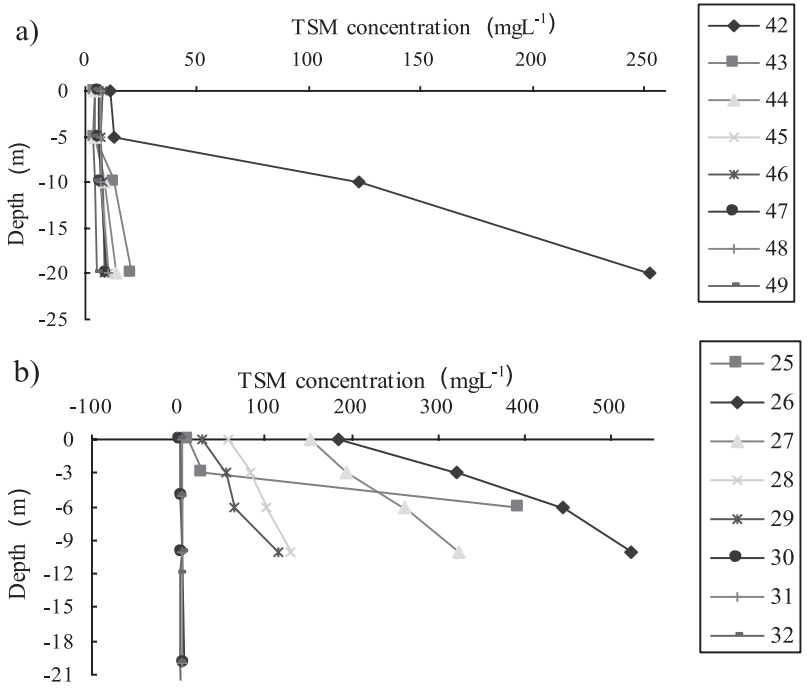

Fig. 3. Vertical distribution of SPM concentrations $\left(\mathrm{mgL}^{-1}\right)$ in spring: a) survey line $32^{\circ} \mathrm{N}$ and b) survey line $34^{\circ} \mathrm{N}$. The numbers in the legend are sampling stations, and the increases in numbers indicate the accretion of distances far from shore.

surface SPM concentration values in autumn are 1/5 of the surface in spring and near bottom SPM concentration values are $1 / 2$ those in spring.

From the vertical distribution of the SPM concentration in autumn, it may be seen that overall it resembles that of spring, except for the lessening of SPM concentration values. On survey line $32^{\circ} \mathrm{N}$, there is only one sampling station (No. 41), of which the SPM concentration values evidently are enlarged with the increase of water depth (Fig. 5a). On survey line $34^{\circ} \mathrm{N}$, the SPM concentration values of all the sampling stations aside from No. 29 increased with the accretion of water. Moreover, the increased range of SPM concentration values became large in the vertical direction with the increasing distance close to the shore (Fig. 5b).

Fig. 5. Vertical distribution of SPM concentration (mgL-1) in autumn: a) survey line $32^{\circ} \mathrm{N}$ and b) survey line $34^{\circ} \mathrm{N}$. The numbers in the legend are sampling stations and the increases in numbers indicate the accretion of distance far from shore.

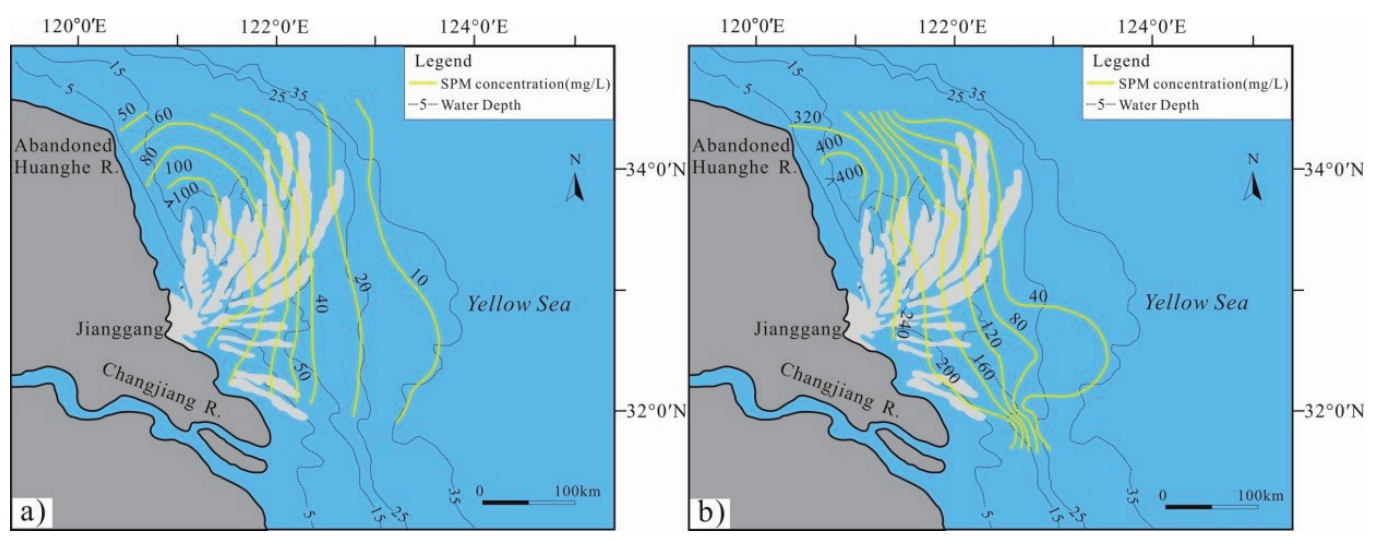

Fig. 2. Horizontal distribution of SPM concentrations $\left(\mathrm{mgL}^{-1}\right)$ in spring: a) surface and b) near bottom. 


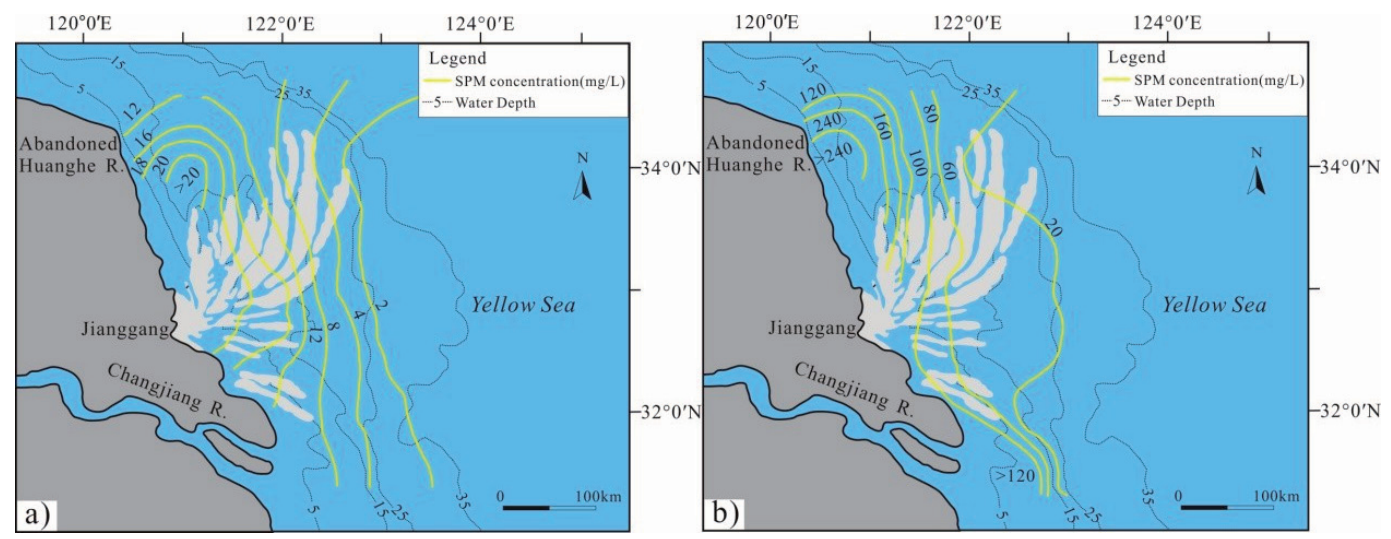

Fig. 4. Horizontal distribution of SPM concentration $\left(\mathrm{mgL}^{-1}\right)$ in autumn: a) surface and b) near bottom.
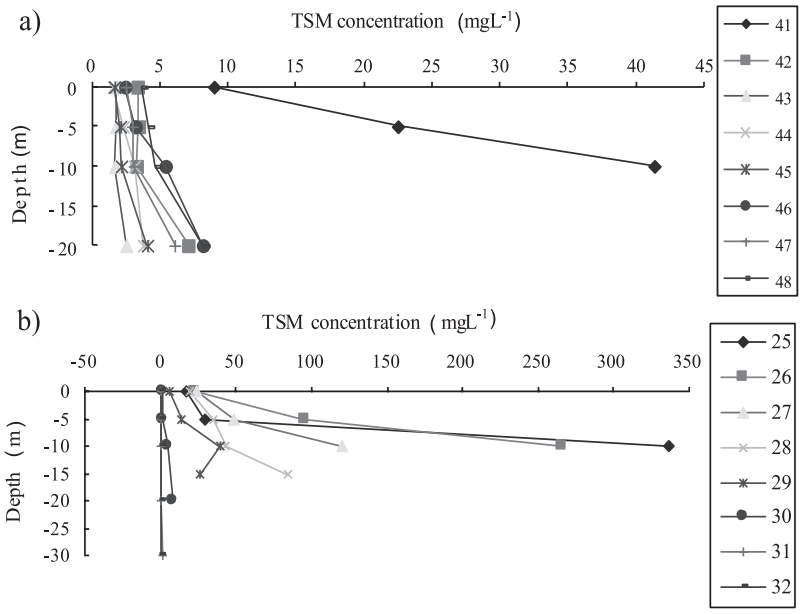

Fig. 5. Vertical distribution of SPM concentration $\left(\mathrm{mgL}^{-1}\right)$ in autumn: a) survey line $32^{\circ} \mathrm{N}$ and b) survey line $34^{\circ} \mathrm{N}$. The numbers in the legend are sampling stations and the increases in numbers indicate the accretion of distance far from shore.

a)

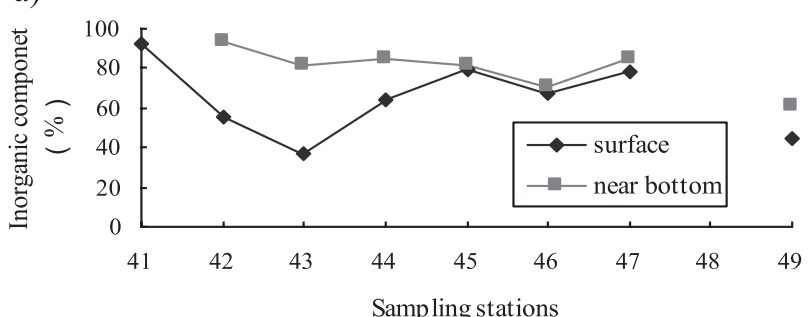

b)

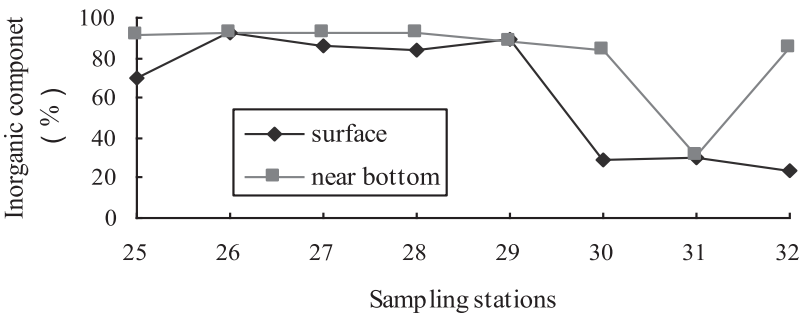

Fig. 6. Across-shore change of SPM inorganic component (\%) in spring: a) survey line $32^{\circ} \mathrm{N}$ and b) survey line $34^{\circ} \mathrm{N}$.

\section{Distribution of SPM Inorganic Component}

SPM is composed of organic and inorganic components. Figs 6 and 7 show that the inorganic component in the surface seawater is much lower than that in the near bottom layer, and its content is reduced across shore in spring and autumn. However, the inorganic component percentage at most sampling stations is more than $60 \%$ in the study area (Figs 6 and 7). This indicates that the main component of SPM near the radial sand ridges area off the Subei Coast is the inorganic component.

\section{Horizontal Distribution of SPM Grain-Size}

SPM grain-sizes in spring and autumn are comparatively fine, with a mean value of $5 \Phi$. The grain size in spring with an average of 5.45 $\Phi$ is a little finer than that in autumn, with an average of $6.13 \Phi$. The coefficient of sorting varies from 1.17 to 1.82 , and most are 1.45 , thus SPM sorting is poor.
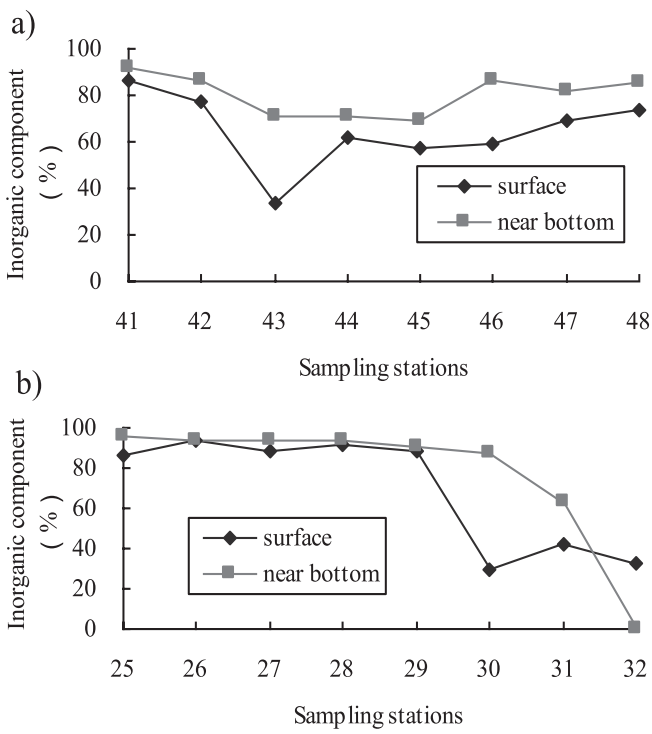

Fig. 7. Across-shore change of SPM inorganic component (\%) in autumn: a) survey line $32^{\circ} \mathrm{N}$ and b) survey line $34^{\circ} \mathrm{N}$. 

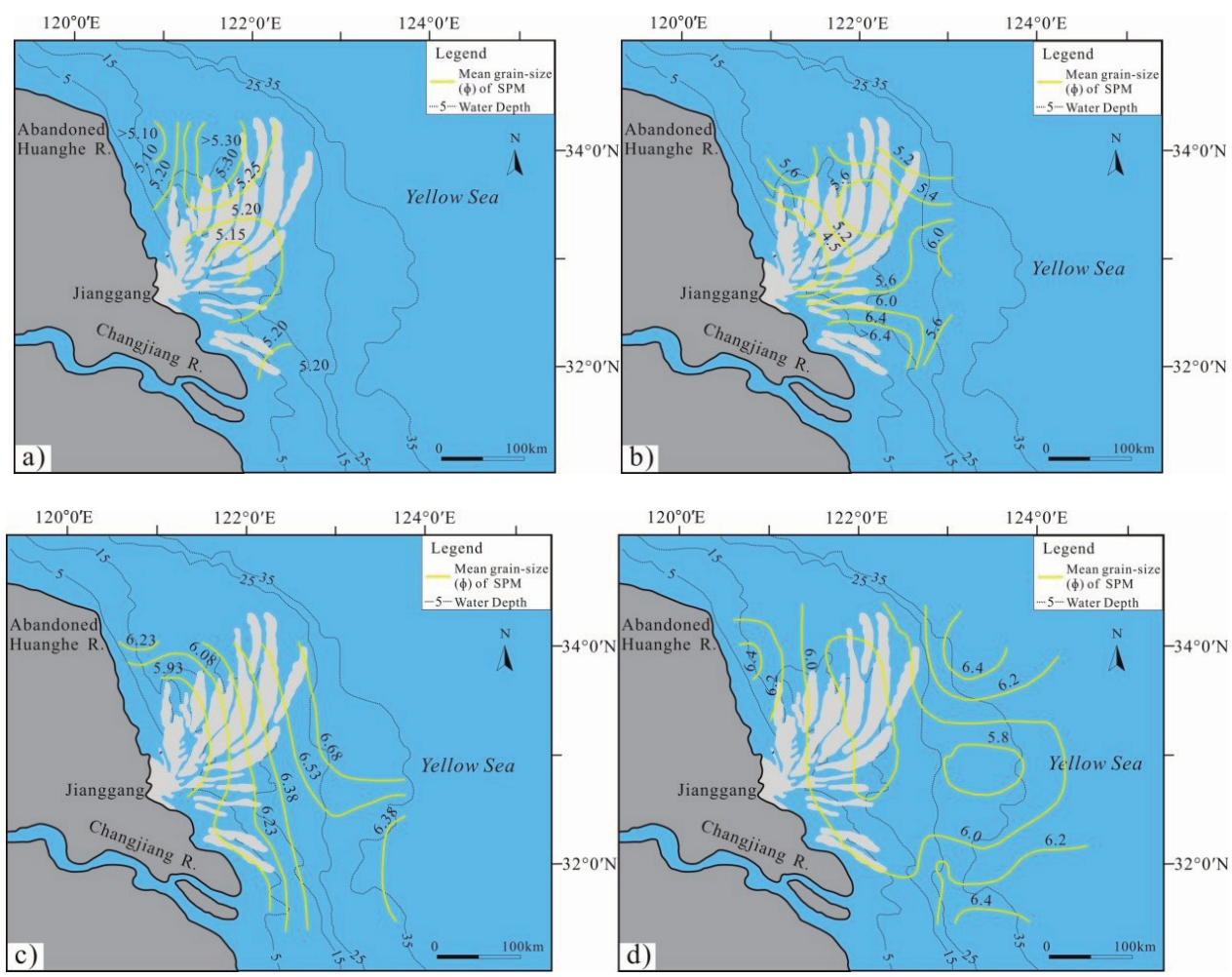

Fig. 8. Horizontal distribution of mean grain-size ( $\Phi)$ of SPM: a) surface in spring, b) near bottom in spring, c) surface in autumn, and d) near bottom in autumn.

Fig. 8 shows that the mean SPM grain size at the surface and near-bottom layers are coarser within the sand ridges area than those at other areas in both seasons, and that the surface SPM is coarser in spring and finer in autumn than the near-bottom one.

\section{Retrieval of SPM Concentrations from Satellite Images}

A significant relationship $\left(\mathrm{R}^{2}=0.944, \mathrm{n}=39\right)$ is observed between the SPM concentrations $\left(\mathrm{mgL}^{-1}\right)$ and Rrs used in this study (Fig. 9). Using the above equation,

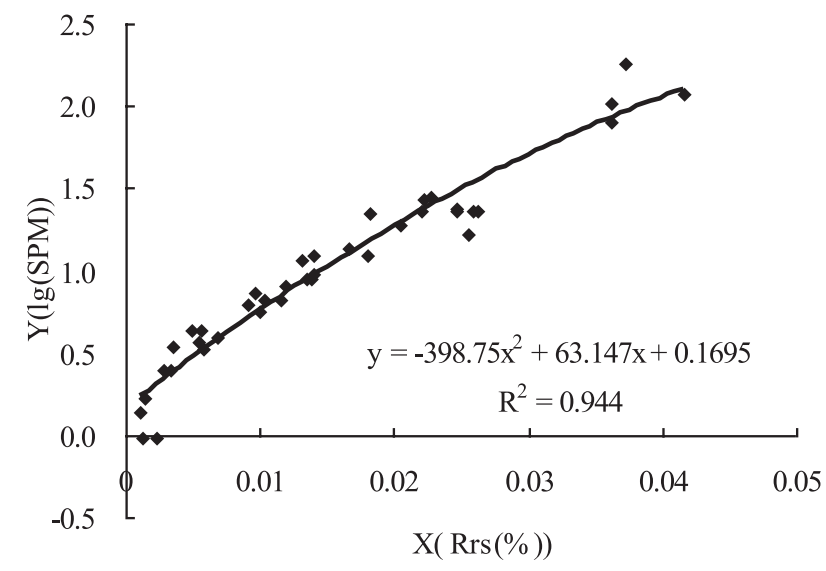

Fig. 9. SPM concentration as a function of in situ remote sensing reflectance (Rrs). a)

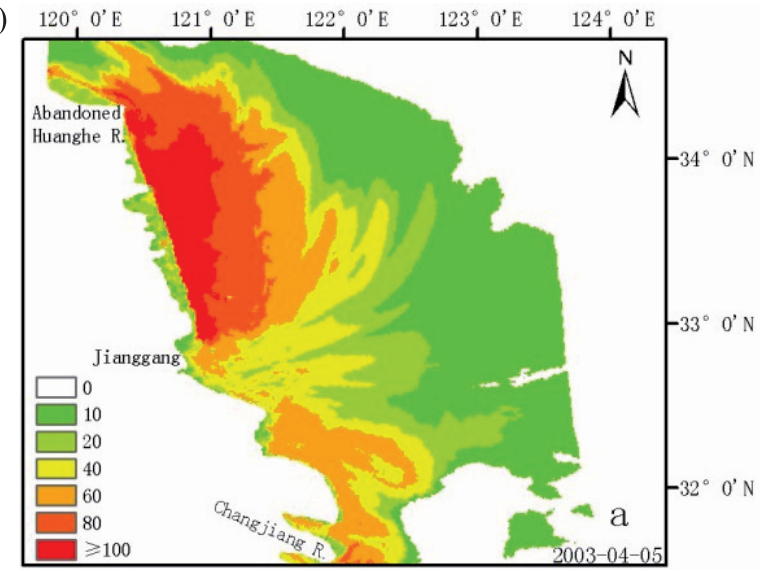

b)

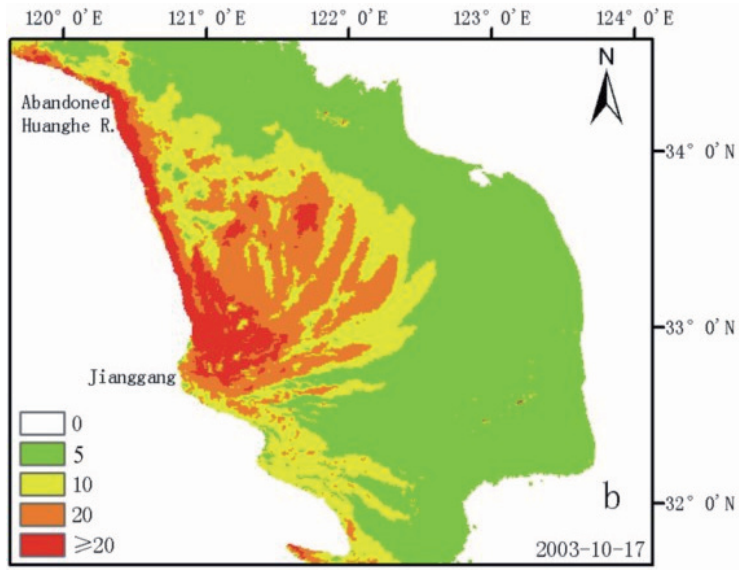

Fig. 10. Remote sensing retrieval of SPM concentrations $\left(m g L^{-1}\right)$ : a) in spring and $\left.b\right)$ in autumn. 
two images respectively obtained in spring and autumn are retrieved SPM concentrations (Fig. 10).

The retrieval results of NOAA/AVHRR band 1 show that SPM concentrations decrease across shore, and higher SPM concentration values are observed near the alongshore area between the Changjiang and abandoned Yellow River. The SPM concentrations exceed $100 \mathrm{mgL}^{-1}$ at the west of $121^{\circ} \mathrm{E}$, and are reduced to $10 \mathrm{mgL}^{-1}$ near $123^{\circ} \mathrm{E}$ (Fig. 10a). In autumn, the horizontal distribution of SPM concentrations resembles that of spring, from an overall perspective (Fig. 10b). However, the SPM concentration values in autumn are generally lower than those in spring, at $1 / 5$ those in spring (Fig. 10b).

In order to test retrieval precision, the in-situ SPM concentrations at nine sampling stations are applied to the retrieval model of $\lg (\mathrm{SPM})=-398.75 \mathrm{Rrs}^{2}+63.147$ $\mathrm{Rrs}+0.1695$. The test results show that the algorithm has a higher retrieval precision with a maximum relative error of $50.3 \%$, minimum relative error of $7.4 \%$, and average relative error of $21.2 \%$.

\section{Source of SPM in Study Area}

The in situ measurements and satellite image retrieval show that the alongshore area between the Changjiang and the abandoned Yellow River has a higher SPM concentration (Figs 2 and 4). This indicates that it is the main source of SPM in the study area. From the comparison between inorganic and organic components (Figs 6 and 7), inorganic material is the main component of SPM - especially in the alongshore area and near the bottom layer. The inorganic material is derived from the resuspending of seabed sediments and riverine inputs [10-11].

Due to the fact that no large rivers have emptied into the near shore area near the radial sand ridges off Subei Coast for many years, the riverine inputs have become scarce. Although the Changjiang is located near the study area with a mean sediment input of $4.6 \times 10^{8} \mathrm{ta}^{-1}$, the riverine inputs mainly move southward and a small quantity of inputs flow into the study area [26]. Under the operation of the Yellow Sea alongshore currents, sediments from the Huanghe River may be transported to the northern Yellow Sea, but cannot reach the study area [27-28]. Previous studies have shown that the total sediment flow into the Yellow Sea from the rivers and Bohai Sea was estimated to be about 2.0-2.5 $\times 10^{7} \mathrm{t}[10]$. The water volume of the Yellow Sea is about $1.7 \times 10^{4} \mathrm{~km}^{3}$, and the maximum SPM concentration value may be about $1.2-1.5 \mathrm{mgL}^{-1}$, based on the assumption that all these sediments are suspended in the sea water, which is far less than the in situ SPM concentration value.

A comparison of the X-ray diffraction spectrum between the near-bottom SPM and seabed surface granule sediment in the radial sand ridge areas show that they have the same matter composition [11, 29]. Therefore, SPM in the study area is mainly derived from the resuspension of the seabed sediment in the radial sand ridges (abandoned Huanghe-Changjiang River multiple delta).

\section{Factors Dominating Distribution of SPM}

Previous studies have demonstrated that wind waves have a noticeable influence on the distribution of SPM. SPM concentrations in winter are more than five times summer values (except the river mouth), which is mostly affected by winter wind waves $[10,21]$. The surface and near-bottom SPM concentrations in spring are much higher than those in autumn, and furthermore, SPM grain size in spring is a little finer than that in autumn, and they are apparently influenced by wind waves too. The investigation data indicated that SPM concentration values increased by one time (surface) and six times (bottom) after strong wind near the radial sand ridges area off the Subei Coast [21].

The progressive tidal wave from the Pacific Ocean through the East China Sea propagates the Yellow Sea, which meets the Shandong Peninsula and then is reflected, forming an anti-clockwise rotary tidal wave system, which meets the progressive tidal wave system from the East China Sea and forms the convergentdivergent tidal current field in the radial sand ridges area off Subei Coast $[10,16]$. The special tidal current field has convergent tidal energy, big tidal range, and strong tidal current so that the radial sand ridges area becomes a sea area of high velocity of tidal currents off the coast with a maximum value up to $140 \mathrm{~cm} / \mathrm{s}$ [14]. The tidal currents are strong enough to erode loose sediments on the sea floor, which make them re-suspended. The resuspended sediments are transported to the outer area of the radial sand ridges by winds and alongshore currents, which cause SPM concentration values in horizontal distribution to decrease across shore (Figs 2 and 4). Due to the weakening of hydrodynamic conditions offshore, vertical changes in SPM concentrations are reduced from coast to sea. Surface and near bottom SPM in spring and autumn are coarser within the sand ridges area than in other areas, owing to a big tidal range and strong tidal currents within the sand ridges area, and comparatively weak hydrodynamic conditions in other areas.

There is an obvious correlative relationship between the distribution of SPM and submarine topography in the periphery of the radial sand ridges. The distribution of SPM in satellite images is basically similar to the spread of submarine sand ridges (Figs 1 and 10). Furthermore, a previous study demonstrated that SPM concentration is low at the center of the tidal trough: medium at both sides, and high at the top of the submarine sand ridges [15]. A comparison of different images and submarine topography showed that the area of higher SPM concentration is mainly limited to within $30 \mathrm{~m}$ water depth, just as the distribution of sand ridges is limited to the same water depth [17]. It can be estimated that submarine topography is one of the important limiting factors for the extension of SPM diffusion. 
Owing to the complicated submarine topography and various hydrodynamic conditions in radial sand ridges of the South Yellow Sea, the impact factors in the distribution of SPM in this study area are complex.

\section{Conclusions}

The main objective of this study is to reveal the spatial distribution and seasonal changes of SPM concentrations near the radial sand ridge areas off the Subei Coast. The results indicate that there are significant differences between the SPM concentrations in spring and those in autumn. The in situ SPM concentrations and satellite image retrieval SPM concentrations have a good corresponding relationship. The results demonstrate that SPM in the study area mainly is derived from the resuspension of the seabed sediments in the radial sand ridges (abandoned Huanghe-Changjiang River multiple delta). Spatio-temporal distribution of SPM near radial sand ridges off the Subei coast is affected by various hydrodynamic conditions.

\section{Acknowledgements}

This work was financially supported by the National Natural Science Foundation of China (NSFC) (41472155, 41106036), a Scientific and Technological Innovation Project Financially Supported by Qingdao National Laboratory for Marine Science and Technology (No. 2016ASKJ13), and Shandong Province Natural Science Fund for Distinguished Young Scholars (No. JQ201311).

\section{References}

1. OFF T. Rhythmic linear sand bodies caused by tidal currents. American Association of Petroleum Geologists Bulletin, 47 (2), 324, 1963.

2. XING F., WANG Y.P., WANG H.V. Tidal hydrodynamics and fine-grained sediment transport on the radial sand ridge system in the Southern Yellow Sea. Marine Geology, 291294 (4), 192, 2012.

3. LI C.X., ZHAO J. Study progress and dispute of Qianggang radial sand ridge in the Northern Jiangsu. Marine Sciences, 4, 57, 1995.

4. LI C.X., ZHANG J.Q., FAN D.D., DENG B. Holocene regression and the tidal radial sand ridge system formation in the Jiangsu coastal zone, East China. Marine Geology, 173 (1), 97, 2001.

5. LI L., SU J.B., RAO W.B., WANG Y.G. Using geochemistry of rare earth elements to indicate sediment provenance of sand ridges in Southwestern Yellow Sea. Chinese Geographical Science, 27 (1), 63, 2017.

6. ZHENG G.L., ZHANG L., ZHUAN X.T., SHANG X.D. A measuring method for three-dimensional turbulent velocities based on vector decomposition and synthesis. International Journal of Heat \& Technology, 33 (4), 51, 2015.
7. SANGMANEE C., WATTAYAKORN G., SOJISUPORN P. Simulating changes in discharge and suspended sediment loads of the Bangpakong River, Thailand, driven by future climate change. Maejo International Journal of Science \& Technology, 7, 72, 2013.

8. HU J.P., ZHANG H.L., LI L., WANG Y.Y., ZHAO M.X. Seasonal changes of organic matter origins and anammox activity in the Changjiang Estuary deduced from multibiomarkers in suspended particulates. Science China (Earth sciences), 59 (7), 1339, 2016.

9. HACISALIHOGLU S., KARAER F. Relationships of heavy metals in water and surface sediment with different chemical fractions in Lake Uluabat, Turkey. Polish Journal of Environmental Studies, 25 (5), 1937, 2015.

10. ZHANG X.H., ZHANG Z. X., LAN X. H., LI R. H. Regional geology of South Yellow Sea, $1^{\text {st }}$ ed, Beijing Ocean Press, 2013 [In Chinese] .

11. YANG Y., WANG Y.P., GAO S., WANG X.H., SHI B.W., ZHOU L., WANG D.D., DAI C., LI G.C. Sediment resuspension in tidally dominated coastal environments: New insights into the threshold for initial movement. Ocean Dynamics, 66 (3), 401, 2016.

12. WEI Q.S., LIU L., ZANG J.Y., RAN X.B. The distribution and transport of suspended matter in the Southern Yellow Sea. Acta Oceanologica Sinica, 34 (2),73, 2012.

13. WEI Q.S., WANG H.W., GE R.F., WANG B.D. Vertical distribution of suspended matter and implications in the Southern Yellow Sea. Advances in Earth Science, 28, 375, 2013.

14. ZHOU C.Y., DONG P., LI G.X. Hydrodynamic processes and their impacts on the mud deposit in the Southern Yellow Sea. Marine Geology, 360, 1, 2015.

15. LIU T., SHI X.F., LI C.X., YANG G. The reverse sediment transport trend between abandoned Huanghe River (Yellow River) Delta and radial sand ridges along Jiangsu coastline of China - an evidence from grain size analysis. Acta Oceanologica Sinica, 31 (6), 83, 2012.

16. CHEN K.F., ZHENG J.H., ZHANG C., WANG N.R., ZHOU C.Y. The evolution characteristics of main waterways and their control mechanism in the radial sand ridges of the Southern Yellow Sea. Acta Oceanologica Sinica, 36 (3), 91, 2017.

17. XU F., TAO J.F., ZHOU Z., COCO G., ZHANG C.K. Mechanisms underlying the regional morphological differences between the northern and southern radial sand ridges along the Jiangsu Coast, China. Marine Geology, 371, 1, 2016.

18. SINGH R.K., SHANMUGAM P. A multidisciplinary remote sensing ocean color sensor: Analysis of user needs and recommendations for future developments. IEEE Journal of Selected Topics in Applied Earth Observations \& Remote Sensing, 9 (11), 5223, 2016.

19. KEITH D.J., SCHAEFFER B.A., LUNETTA R.S., GOULD JR R.W., ROCHA K., COBB D.J. Remote sensing of selected water-quality indicators with the hyperspectral imager for the coastal ocean (HICO) sensor. International Journal of Remote Sensing, 35 (9), 2927, 2014.

20. LIU X., FENG X.L., LIU J., LIN L. Laboratory application of laser grain-size analyzer in determining suspended sediment concentration. Journal of Ocean University China (Oceanic and Coastal Sea Research), 13 (3), 375, 2014.

21. LIU T., SHI X.F., LIU Y.G., LIU S.F., WANG K.S. Diffusion of sediment in radial sand ridges in Southern Yellow Sea. Oceanologia Et Limnologia Sinica, 45, 32. 2014. 
22. WANG X.Y., TANG J.W., LI T.J., ZHOU H.L. key technologies of water spectra measurements with abovewater method. Ocean Technology, 31 (1), 72, 2012.

23. JU J.C., ROY D.P., VERMOTE E., MASEK J., KOVALSKYY V. Continental-scale validation of modisbased and ledaps landsat etm + atmospheric correction methods. Remote Sensing of Environment, 122 (1), 175, 2012.

24. YANG G., HE H.L., WANG Y., HAN X.Q., WANG Y.J. Evaluating a satellite-based sea surface temperature by shipboard survey in the Northwest Indian Ocean. Acta Oceanologica Sinica, 35 (11), 52, 2016.

25. NOVOA S., DOXARAN D., ODY A., VANHELLEMONT Q., LAFON V., LUBAC B., GERNEZ P. Atmospheric corrections and multi-conditional algorithm for multisensor remote sensing of suspended particulate matter in low-to-high turbidity levels coastal waters. Remote Sensing, 9 (1), 61, 2017.

26. LIU X., LI G.X., MA Y.Y., DING D., DADA O.A., XU J.S., QIAO L.L., LI J.C., LIU S.D. Distribution and diffusion of surface suspended matter off the East China Shore, 2010. Geological Journal, 51 (S1), 49, 2016.

27. WEI Q.S., WANG H.W., GE R.F., WANG B.D. Vertical distribution of suspended matter and implications in the Southern Yellow Sea. Advances in Earth Science, 28 (3), 374, 2013.

28. MILLMAN J.D., YANG Z.S., Chinese-U.S. sediment source-to-sink research in the East China and Yellow Seas: Abrief history. Continental Shelf Research, 90, 2, 2014.

29. QIN Y.S, LI F., XU S.M. Suspended matter in the South Yellow Sea. Oceanologia Et Limnologia Sinica, 20 (2), 101, 1989. 